\title{
La «Relación de lugares y pueblos donde se saca la grana de la Ciudad de Cholula» (México) de 1600. Alcance y contenido
}

\author{
Roberto GARCÍA-MORÍS \\ Universidad de Granada \\ rmoris@uco.es
}

Recibido: 18 de agosto de 2013

Aceptado: 3 de octubre de 2014

\begin{abstract}
RESUMEN
Asturias ha sido una región emigrante y América uno de los destinos más buscados por muchos de los asturianos emigrantes desde tiempos de la Edad Moderna. Fruto de esas migraciones, los archivos nobiliarios asturianos albergan algunos documentos que hacen referencia explícita al territorio americano o a las estancias de asturianos en América. En este trabajo se pretende dar a conocer un documento «americano» que hace referencia exclusiva a un territorio de América, la ciudad de Cholula (México) y que se conserva descontextualizado en un fondo nobiliario del occidente de Asturias. En él se hace una descripción cuantitativa y cualitativa del número de nopales y su cultivo en la Cholula del siglo XVI. Se realiza también un análisis de la naturaleza del documento como fuente histórica en relación con el fondo documental en el que se custodia y se contrasta con obras contemporáneas.
\end{abstract}

Palabras clave: Cholula, Asturias, grana cochinilla, nopales, patrimonio documental, emigración.

\section{"List of Places and Villages Where to Extract Cochineal in the City of Cholula» (Mexico, 1600). Scope and Content}

\begin{abstract}
Asturias has traditionally been an emigrant region and America one of the most preferred destinations for the many of Asturian emigrants since Modern Age. As a result of this migrations, Asturian family (o noble) archives keep some documents which make explicit reference to the American territory or/and to the stay of Asturian citizens in America. The purpose of this contribution is to make known an «American» document about an American territory called the city of Cholula (Mexico), and that is kept decontextualized in a noble collection in the west of Asturias. It makes a quantitative and qualitative description of the number of nopales and its cultivation in Cholula in the 16th century. At the same time, an analysis of the nature of the document is carried out as an historical source of information, in parallel that is linked to the documentary fund where is guarded, as it is shown contemporary works.
\end{abstract}

Key words: Cholula, Asturias, cochineal grain, nopales, documentary heritage, migration.

Sumario: 1. Introducción. 2. Contextualización del documento. 3. Estudio del documento. 4. Conclusiones. 5. Referencias documentales. 6. Referencias bibliográficas.

\section{Introducción}

En los últimos años, en el transcurso de la elaboración de mi Tesis Doctoral, he visitado numerosos archivos hallando en ocasiones documentos que, si bien no son prioritarios para la temática de mi investigación doctoral, pues hacen referencia a otros espacios históricos, sí interesan para un tratamiento individual, por su peculiaridad y singularidad dentro del patrimonio documental asturiano. Este es el caso del documento conservado en el Archivo Histórico de Asturias, dentro del Fondo perteneciente al Palacio de El Pividal (Abres, Vegadeo), presentado en esta ocasión y denominado «Relación de 
los lugares y pueblos donde se saca la grana de la Ciudad de Cholula y sus subxetos...», de 1600 (AHA, Fondo Pividal, C11249/01). En estas páginas se realiza una presentación del documento y su naturaleza, vinculándolo con los espacios históricos a los que hace referencia, ya sea de manera directa, la ciudad de Cholula (México), o indirecta, el Fondo del Palacio de El Pividal (Abres, Vegadeo), así como con la familia que lo custodió desde el primer momento, con la intención en un futuro de estudiar a fondo el documento explotando todas sus posibilidades históricas.

Asturias ha sido una región emigrante y América uno de los destinos más buscados por muchos de los asturianos desde la Edad Moderna. En el occidente de Asturias, al igual que en otras zonas de la región, se pueden constatar en las fuentes, en relación con el vecindario del que forman parte, asturianos que emigraron a América desde al menos el primer tercio del siglo XVII ${ }^{1}$. Fruto de esas migraciones, los archivos nobiliarios asturianos albergan algunos documentos que hacen referencia explícita al territorio americano o a las estancias de asturianos en América. En este caso, se presenta un documento que he denominado «americano», pues hace referencia exclusiva a un territorio de América, la ciudad de Cholula (México), y que se conserva, ciertamente descontextualizado, en un fondo nobiliario del occidente de Asturias.

En el documento se realiza una descripción cuantitativa del número de nopales y de la grana, dando algunas pistas sobre su cultivo, en los lugares que conformaban la Cholula de finales del siglo XVI. A través de este trabajo se pretende llamar la atención sobre un documento conservado en un fondo (nobiliario y asturiano) que nada tiene que ver con su naturaleza y contexto histórico, si bien su presencia en él puede explicarse por la estancia de algunos miembros de la familia generadora del mismo en el continente americano, más concretamente en México.

\section{Contextualización del documento}

\subsection{El Corregidor Vasco López de Vivero}

El Fondo del Palacio de El Pividal está en su conjunto bien conservado y forma parte del patrimonio documental del Archivo Histórico de Asturias desde 2002, cuando su propietario, José Joaquín Milans del Bosch, realizó su depósito. Recibe el nombre del lugar donde fue custodiado, el Palacio de El Pividal, situado en la parroquia de Santiago de Abres, perteneciente al actual concejo de Vegadeo. Tal y como puede observarse en el inventario del Archivo Histórico ${ }^{2}$ de Asturias, este fondo alberga documentos comprendidos en un intervalo de tiempo que se inicia a finales de la Edad Media (1452) y llega hasta casi el último tercio del siglo XIX (1867), con un número

\footnotetext{
1 Los documentos albergados en los archivos nobiliarios (entre otras fuentes) aportan pistas sobre asturianos emigrados desde fechas anteriores al siglo XVII. No obstante, si lo que se pretende es ofrecer una panorámica más general de la representatividad del colectivo emigrante y emigrante americano sobre el vecindario al que éstos pertenecen, hay que acudir a las fuentes municipales (fundamentalmente Padrones de Moneda Forera, ver García Morís 2008), que raras veces se conservan con anterioridad a las primeras décadas del siglo XVII, al menos en los concejos más occidentales de Asturias.

2 El inventario del Fondo del Palacio de El Pividal puede consultarse en red, a través de la página www. archivosdeasturias.info.
} 
importante de documentos relativos a la Edad Moderna, organizado en once cajas generadas por las familias Vivero ${ }^{3}$, Miranda y Queipo del Llano. El documento se insertó, dentro del cuadro de clasificación del fondo nobiliario, en «Escritos personales y profesionales», no sin calificarlo previamente como «curioso». La vinculación de los individuos generadores de esta documentación con América debe establecerse, no por la conservación en el fondo familiar del documento americano de 1600, sino de otros, principalmente testamentos, algunos de ellos vinculados al fundador del mayorazgo en 1609, Vasco López de Vivero, Corregidor de México, y que se realizaron durante sus estancias en América y las de su familia, o haciendo referencia a ellas ${ }^{4}$.

Desde finales del siglo XVI el fondo alberga testamentos de asturianos en México que coinciden cronológicamente con el documento, como el testamento de Dominga de Veldedo, mujer de Vasco López de Vivero, otorgado en dicha ciudad en 1597 (AHA, Fondo Pividal, C11248/04), el traslado del testamento (AHA, Fondo Pividal, C11248/09), el memorial y recibos de lo que se gastó en las exequias y entierro de ésta en la ciudad de México (AHA, Fondo Pividal, C11248/21) o el testamento del propio Vasco López de Vivero, otorgado en el mismo lugar el 12 de abril de 1607 que contiene los bienes que forman el mayorazgo (AHA, Fondo Pividal, C11248/01 [a]) de la familia Vivero en el año de su institución.

Vasco López de Vivero Navia y Villamil fue quien muy probablemente aportó el documento al archivo familiar, pues era, en el entorno cronológico de su confección (1600), Corregidor de la ciudad de México y consultor del Santo Oficio de la Inquisición en dicha ciudad, tal y como aparece reflejado literalmente en la documentación conservada en el fondo documental y que más adelante se relacionará con los otros documentos generados por López de Vivero y su familia. Cuando fundó el mayorazgo, los bienes para su fundación pertenecían tanto a Asturias como a la vecina Galicia (el Corregidor era natural de Mondoñedo, Lugo). Junto a las casas principales sitas en Mondoñedo, propiedades y medias propiedades, bienes como lagares, palomares, hornos, tierras, viñas, molinos, pumaradas y juros, en lugares como Lorenzana, o Piantón, entre otros, conformaban los bienes del recién instituido mayorazgo ${ }^{5}$.

Por todo ello, es necesario vincular el documento objeto de esta aportación con el occidente asturiano y más concretamente con Vegadeo, debido a que llegó hasta nosotros por su conservación dentro del fondo del Palacio de El Pividal (Abres, Vegadeo), custodiado por las familias que generaron el resto de documentos que junto a él se conservan. El documento forma parte del patrimonio documental familiar, no siendo generado por la familia Vivero, aunque sí aportado previsiblemente por sus miembros al archivo familiar. El otro espacio geográfico al que directamente hace referencia el documento es la ciudad mexicana de Cholula, pues trata del cultivo del

\footnotetext{
3 Según el Censo Guía del Archivo Histórico de Asturias, el fondo custodia documentos del mayorazgo de los Rivero, fundado por Vasco López de Rivero, en 1609. Hay un error de transcripción, pues no se trata del mayorazgo de los Rivero sino de los Vivero, fundado efectivamente en 1609 por Vasco López de Vivero, no de Rivero.

${ }^{4}$ Los datos relativos a la fundación del mayorazgo, así como a las familias generadoras de la documentación han sido extraídos del Censo Guía del Archivo Histórico de Asturias, consultando posteriormente algunos de los documentos de más interés para el presente trabajo.

5 Por el mejor estado de conservación que presenta, conservado en el mismo legajo, pero fechado en 1703, interesa: AHA, Fondo Pividal, C11248/01 [b].
} 
nopal y la grana en sus términos, en el cambio del siglo XVI al XVII. La ciudad de Cholula es considerada por la historiografía uno de los lugares más importantes del centro de México en la América prehispánica, protagonismo que cederá a la vecina ciudad de Puebla, aunque siga destacando por su papel agrícola (Ruz 2008: 8), especialmente en los que se refiere al cultivo de la grana o cochinilla.

Podemos indagar aún más sobre Vasco López de Vivero ${ }^{6}$. Natural de Mondoñedo (Lugo, Galicia), fue nombrado Corregidor de México en 1588 y sustituido por Francisco Muñoz Monforte en 1596. De sus viajes a América se conservan algunos documentos $^{7}$, generados por él mismo y por quienes le acompañaron. Entre esos familiares se encontraba su mujer, Dominga de Veldedo ${ }^{8}$, natural de Ribadeo y por varios criados, entre los que destacaban algunos de sus familiares directos o de su mujer. El viaje a México lo realizó en torno a 1590, cuando tenía aproximadamente cuarenta años, con su mujer, de unos veintiocho y junto a los tres hijos del matrimonio: Antonio de ocho años, Ana María de seis y Catalina de cuatro. Entre las personas al servicio del Corregidor, seis criados y dos mujeres ${ }^{9}$, se encontraba Aldonza de Veldedo, sobrina directa de la mujer del Corregidor y Juan Fernández de Navia y Tineo, mozo soltero, natural de Navia de unos veintidós años, sobrino de Vasco López de Vivero (AGI, Contratación, 5233, N. 42).

No debe resultar extraño, sino más bien común, la vinculación existente entre la familia Vivero y América, pues las migraciones de asturianos al nuevo continente, aunque no se dieron con la importancia cuantitativa que sí experimentaron otras regiones de España, fueron una constante en la Edad Moderna (Martínez Shaw 1994). Los movimientos poblacionales de Asturias a América existieron a lo largo de la modernidad y, en mayor medida, en la Edad Contemporánea. No puede entenderse la existencia de este documento en un fondo asturiano sin tener en cuenta que numerosos asturianos emigraron a América, retornando a sus lugares de origen en muchos casos. Estos movimientos de población en la zona que nos ocupa ya se han detectado en los documentos municipales del siglo XVII de algunos de los municipios que conformaban la zona occidental asturiana en la época y que, como se ha señalado, relacionan la representatividad de los emigrantes americanos con su vecindario y con sus vecinos emigrantes. Por ejemplo, durante el siglo XVII, en San Tirso de Abres, concejo de esa zona, el destino de hasta un 7\% de los vecinos que emigraron fue Las Indias (García Morís 2008; 2012). La emigración asturiana a América no fue, por tanto, extraña en el siglo XVII, tal y como sucede en otros territorios diferentes al occidente asturiano, sobre los que llamaron la atención otros autores ${ }^{10}$.

${ }^{6}$ Se encuentra en proceso de elaboración un pequeño trabajo sobre Vasco López de Vivero, fruto del cruce de fuentes de diferentes archivos. Algunos de esos datos se adelantan en el presente texto.

7 En el Archivo de Indias se pueden consultar algunos pasajes a Indias tanto de Vasco López de Vivero, como de las personas que lo acompañaron en su estancia como Corregidor en México.

8 Conocemos por su testamento, conservado en el mismo fondo documental, que Dominga de Veldedo murió siendo aún corregidor Vasco López de Vivero, el 16 de octubre de 1597, entre las diez y las once de la noche. Fue enterrada al día siguiente en la Iglesia Mayor de México.

9 Interesa, sobre el papel jugado por los corregidores, así como sobre su origen social y las gentes que a su servicio les acompañaron a América, una contribución de $M^{\mathrm{a}}$ Luisa Pazos (2003: 445-455), en la que se refiere a varios corregidores gallegos.

10 La emigración asturiana a América ha sido tratada por varios autores tales como: Anes1987; Ansón 1991; Barreiro 1991; Barreiro y Ureña 1992; Martínez Cachero 1976. 


\subsection{Cholula y la grana o cochinilla}

Una aportación importante en los estudios realizados sobre el cultivo de la cochinilla se debe a la etnóloga Dahlgren (1990), en cuya obra rescata varias fuentes históricas que versan sobre este cultivo. En el prólogo de su obra señala que:

«Se trata de minúsculo insecto hemíptero y se cría sobre ciertas especies de nopales. Se distingue entre dos tipos de cochinilla, la fina (cultivada) y la silvestre, que presentan diferencias bien marcadas. (...) El tinte se obtiene del cuerpo disecado de la hembra, cuyo ciclo de vida y reproducción es de tres meses» (Dahlgren 1990: 11-12).

La grana o cochinilla es el colorante más conocido de los que se produjeron en la América colonial. Sobre él se han realizado numerosos trabajos iniciados ya en la propia Edad Moderna (Sarabia 1992; 1994; 1998) y que prosiguen en la actualidad, por lo que referirse a todos ellos sería tarea imposible. También en torno a su historiografía se han producido algunos errores de interpretación histórica sobre los que Villaseñor (2010) ha llamado la atención en una exhaustiva revisión.

Sarabia (1998) argumentó la importancia de la grana con base en la normativa y en los cargos que se crearon para el trabajo de los indígenas en este tipo de producción y es que, ya en 1539, el cultivo de la cochinilla estaba incluido en los tributos y en 1572 se creó la figura del juez de la grana, con sede en Puebla de los Ángeles. Era tal la importancia de este producto que llegaron a producirse fraudes, "echándole una especie de betún rojizo para que pesara más» (Sarabia 1998: 1831), lo que provocó que el virrey Velasco ordenara en 1555 a varios corregidores, entre ellos al de Cholula, inspeccionar la calidad de la grana cochinilla. Fue ese mismo virrey el que informó a Felipe II en 1557 sobre «la riqueza de la grana explotada por los indígenas de Tecamachalco y Cholula, dando unas cifras anuales de ventas superiores a los 50000 ducados» (Sarabia 1998: 1831). Esta producción siguió aumentando a lo largo del siglo XVI debido, fundamentalmente, a la demanda que los conquistadores realizaron de este producto como colorante, desplazando a otros cultivos tradicionales y a la que se solicitaba desde España, hasta tal punto que el siglo XVI «terminaba con un mejor conocimiento científico y técnico de este producto tintóreo tan demandado en Europa y que ocupaba ya el segundo lugar en las cargas de las flotas, tras los metales preciosos, alcanzando cifras considerables en los mercados textiles europeos» (Sarabia 1998: 1834). Giordano (2010: 123) señala que «los españoles que acaparaban la producción exportaban grandes cantidades a Europa y el resto se empleaba principalmente para teñir las telas que se producían en los obrajes de Tlaxcala, Puebla, Cholula y áreas circunvecinas».

Sobre la comercialización mundial de este producto, Sánchez y Suárez (2006) presentaron un trabajo relativamente reciente en el que abordan tanto la producción como el comercio de la grana entre los siglos XVI y XIX. Su importancia se extiende hasta la Edad Contemporánea cuando, paulatinamente, será desplazado por los tintes químicos de finales del siglo XIX ${ }^{11}$. Entre los nuevos centros productores que toman protagonismo en este siglo, debido a la crisis colonial, se encuentran las Islas Canarias.

11 Sobre el comercio de la grana, entre otros productos, ver asimismo el trabajo de Zabalza (2015). 
Ruz (2008) realiza una breve, pero exhaustiva, revisión histórica de la importancia de Cholula en la América prehispánica y colonial en el entorno del siglo XVI. La ciudad comenzará prontamente una importante relación con la población colonial de Puebla, fundada en 1531, que Ruz (2008: 16) ejemplifica precisamente en el desarro1lo «del comercio de la grana cochinilla, producto que fue bastante importante durante el siglo XVI en la región» y Sarabia (1998: 1830) señala que «abundan las órdenes específicas para la zona poblana, vinculadas directa o indirectamente con este tinte».

El final del cultivo de la grana en Cholula y la zona en la que se sitúa, se produjo en torno a 1663 (Castillo 2001) debido, en parte, a tres causas fundamentales: el bajo precio que se pagaba a los productores locales, los impuestos con los que se gravó el cultivo y las crisis epidémicas que afectaron a los productores y cultivadores de la cochinilla (Sánchez Silva 1998).

Con el fin de justificar y contextualizar el origen, presencia, y conservación del documento americano en el marco del patrimonio documental asturiano, y a modo de recapitulación de lo expuesto en los subapartados anteriores, puede concluirse que la vinculación del documento de 1600 con su espacio o espacios históricos se explica por las razones históricas mencionadas. Unas son aplicables al marco de Asturias debido a la existencia del fenómeno migratorio experimentado por los asturianos de la Edad Moderna, y más concretamente de los concejos más occidentales en su tránsito hacia los municipios lucenses más orientales, desde al menos finales del siglo XVI; y específicamente por la pertenencia de esos asturianos al estamento noble, en su mayoría al colectivo de hidalgos que formaron parte de las generaciones de españoles dominadores del espacio americano, bajo las distintas figuras de dominio territorial y administrativo, como parece ser el caso de Vasco López de Vivero, Corregidor de México. Otras son aplicables al territorio americano, a la América Colonial, al dominio de los territorios por parte de España, la explotación de sus recursos y sus gentes, y el balance y cuantificación de ese dominio económico de los llamados «indios» y su trabajo, como se desprende del inventario de nopales cultivados en la ciudad de Cholula en el tránsito del siglo XVI al XVII y sus vecinos, así como de las sencillas descripciones que sobre ellos se realizan. Finalmente, ha de notarse la importancia de la grana cochinilla, y su comercio desde México, un insecto que daba un tinte rojo, excelente para tejidos de seda, vinculado al cultivo del nopal (Céspedes 1983: 136).

\section{Estudio del documento}

\subsection{Estructura y marco geográfico del documento}

El documento, que se encuentra en buen estado de conservación, está formado por cincuenta y dos folios escritos, con alguna excepción, por el anverso y el reverso, numerados en el folio recto. Presenta una encuadernación aparentemente posterior, en la que los distintos folios que lo componen se conservan «cosidos». El documento comienza con una hoja ilustrada (Figura 1), que fue numerada como folio seis, pasando directamente al folio ocho, donde empieza el documento denominado «Relación de los lugares y pueblos donde se saca la grana...», ciertamente desencajada, excepto 
Figura 1: Dibujo del cultivo de la grana en el nopal contenido en el documento de 1600 .

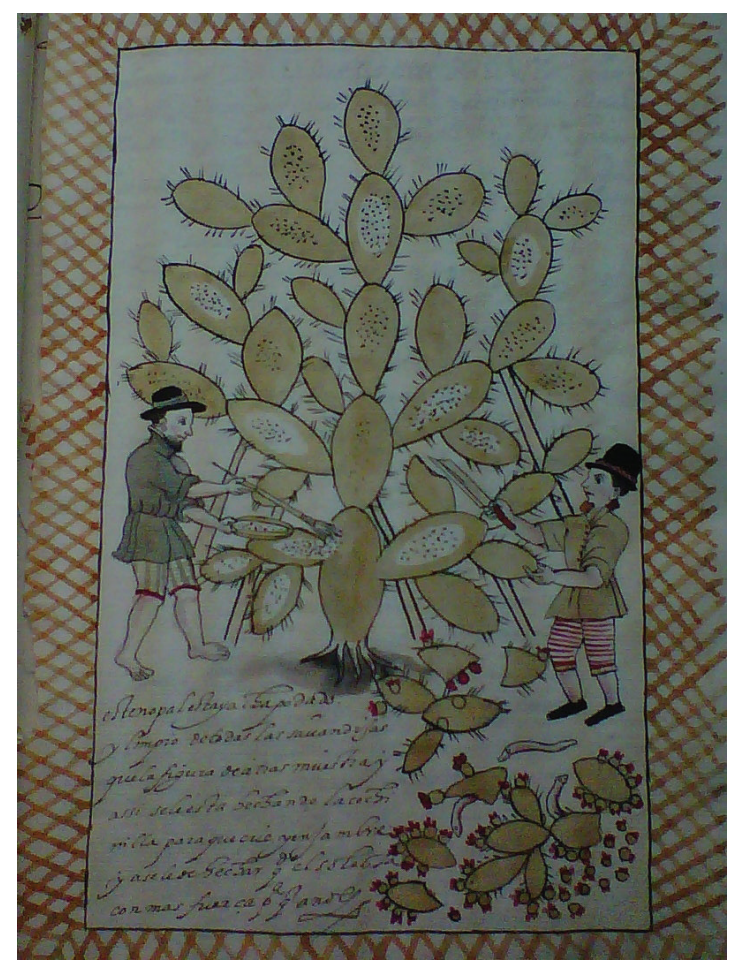

por su temática, del conjunto documental. La totalidad del documento, que presenta la misma grafía, clara y cuidada, guardando el mismo formato en su globalidad, fue elaborado por Alonso de Nava, Juez de Comisión «para beneficio de ella». Los folios cuentan con márgenes, tanto a su izquierda como a su derecha a lo largo de todo el documento, donde se registran el número de nopales nuevos (margen izquierdo) y nopales viejos (margen derecho) de cada estancia.

El documento se estructura en cuatro partes diferenciadas, división que se puede establecer tomando como criterio el espacio geográfico, siguiendo todas ellas el mismo esquema en estancias y reflejando el número de nopales en sus márgenes, precedidas de una introducción del término al que se adscriben cada una de las estancias «catastradas». Para la presentación del documento se recogerán aquellas informaciones de tipo cualitativo, descriptivas del cultivo y de la idoneidad del territorio catastrado para la explotación de las nopaleras y de la grana.

La primera parte del documento abarca dieciséis folios y hace referencia a la ciudad de Cholula, entre el folio ocho recto y el dieciséis vuelto ${ }^{12}$. El contenido descriptivo se inicia en el folio ocho, primer folio con texto, que contextualiza el documento en «la ciudad y cavecera de Cholula» que «está fundada en muy apacible sitio» ${ }^{13}$ don-

12 El folio dieciséis es el único que aparece suelto en el bloque documental.

13 Conocemos, a través de la «Relación de Cholula» de 1581 realizada por Gabriel de Rojas (Corregidor de Cholula) que «... hay un temple muy sano y templado...» y que «es abundante en aguas...» (Rojas 1985: 123-145). 
de existen «muy fructuosas tierras» en las que se da «qualquier planta muy bien, y en particular la grana» ${ }^{14}$ «con mucha fertilidad». La grana está presente «en abundancia porque los yndios de allí son más ynteresados que los demás de esta Nueva España por las muchas grangerías» $\mathrm{y}$ «tienen particular cuydado en cultibarla», «por el rigor con que se castigan sino lo hacen», pues es importante «para ellos y para este Reyno». Gabriel de Rojas (1985: 126) en 1581 los calificó como «hábiles», «de ingenio», que «muestran mucha agilidad». Comienza por la ciudad cabecera de Cholula ${ }^{15}$ y por sus estancias, para desde el folio catorce recto, continuar con «las estancias que agora se siguen» «subjectas a San Gabriel de Cholula» que «las doctrinan los frayles de San Francisco ${ }^{16}$ de la parroquia de San Andrés». Prosigue con la ciudad de los Ángeles ${ }^{17}$, donde «plantan los naturales los nopales con mucho trabajo, por los continuos daños que de hordinario reciben». La ciudad está situada en un llano y cuenta con un arroyo.

La segunda parte hace referencia a la ciudad de Guexosingo ${ }^{18}$, a lo largo de catorce folios. Desde el folio dieciocho ${ }^{19}$, se recogen los cultivos pertenecientes a la «ciudad y cabecera de Guexosingo» donde «se da la grana muy bien ${ }^{20}$ y con mucha fertilidad, por ser la tierra de buen temple y fructuosa, aunque por los nuebos vezinos españoles que allí se an avezindado, la tienen destruyda». Por ello, «desmayan los naturales en bolber a plantar más nopales porque quando están criando en dos y tres años, se los destruyen y comen (los ganados) en un día y noche. Porque las cercas que tienen los nopales tienen «poca defensa». El principal problema que se encuentra en la ciudad de Guexosingo y que parece ser común al territorio, pues el documento señala que «este mismo daño corre generalmente en esta provincia», es la presencia del gana$\mathrm{do}^{21}$. «Por estar poblada de labores de españoles, y al tiempo de la seca no hallan que comer los ganados», que al ser muchos, los indios no pueden estar al cuidado

14 Es tan fértil y apacible que, Gabriel de Rojas cita numerosas plantas, ornamentales y de consumo, «hay mucha diversidad de flores, como son clavelinas, lirios y azucenas de España, y otras flores de la tierra», recoge en la respuesta tercera (Rojas 1985: 125). En la veintitrés, llama la atención sobre los frutales, «de las frutas de España hay gran cantidad, como son albaricoques, peras, melocotones...», (Rojas 1985: 136), así como en la veinticinco, donde se planteaba el cultivo de verduras «Las hortalizas y semillas de España que se dan muy bien son coles, lechugas, rábanos, ajos, cebollas, nabos y zanahorias, no se coge trigo ni cebada, ni lo demás.» (Rojas 1985: 137).

15 En la respuesta siete, Gabriel de Rojas indica que «está situada (...) a veinte leguas de la de México, donde reside Real Audiencia, a la parte del leste» (Rojas 1985: 127) contestando a la dieciséis que «el asiento de esta ciudad no tiene más nombre particular que Cholula, que así se pronuncia entre españoles: es en el Obispado de Tlaxcallan» (Rojas 1985: 135).

16 El monasterio de San Francisco aparece también en las Relaciones de Gabriel de Rojas en respuesta a la última pregunta (la treinta y seis), donde se interrogaba sobre los monasterios de frailes y monjas de cada orden (Rojas 1985: 144).

17 «Tiene esta ciudad (Cholula) a la de los Ángeles a la banda del leste, a legua y media de camino llano y derecho» (Rojas 1985: 127).

18 «A la parte del noroeste, tiene a la ciudad de Huexotzinco, pueblo de indios que dista dos leguas grandes por camino llano y derecho» (Rojas 1985: 127).

${ }_{19}$ Carece el documento del folio diecisiete, si bien culmina la relación de nopales de Cholula y no rompe el inicio de la segunda parte perteneciente a Guexosingo.

${ }^{20}$ Los términos utilizados para calificar el modo en que se da la grana a lo largo de las estancias son de «buen»y «muy bien».

21 En la respuesta cuatro, Gabriel de Rojas señala que «es tierra abundosa de mantenimientos y frutos, y falta de pastos y montes, por ser poca tierra y estar toda cultivada de sementeras y nopales, en que se recoge la grana» (Rojas 1985: 126). 
de sus casas continuamente. Además, señala el documento, que cuando los indios toman medidas respecto a la intrusión del ganado en las nopaleras, los «maltratan y aporrean (los españoles) y con este temor y la poca satisfacción que de ello tienen, les hace desmayar en el beneficio de la dicha grana». La cuantificación de los nopales se acompaña de algunas pistas de la presencia de comunidades religiosas, concretamente en Guexosingo, de la que se dice es «adoctrinada» por frailes de San Francisco, residentes en el Convento de San Miguel, una ciudad con novecientos vecinos ${ }^{22}$. En la misma relación se incluye la Villa de Carrión ${ }^{23}$.

La tercera parte del documento se refiere al pueblo de San Andrés Calpa, catastrado en ocho folios, donde «se da la grana muy bien por su gran fertilidad, por ser la tierra de apacible temple y fructuosa», pues el pueblo se encuentra «cerca del bolcán y en la falda de la sierra nevada de donde le baxan muchos arroyos de agua, no es muy llano» ${ }^{24}$.

Finalmente, se encuentra la cuarta parte del documento referida a San Salvador de Tlalnepantla, formada por los últimos diez folios. En el primero, se presenta un dibujo de la «adbocación del pueblo y cabecera de San Salbador con sus tres barrios» y de dos aves de la zona, el «quetzalan» y el «astatotoaco», incorporando colores en todas sus figuras. En San Salvador, al igual que en territorios anteriores, vuelve a aparecer el efecto destructor sobre los nopales de los ganados, siendo la tierra muy fértil para el cultivo por su situación y por la disponibilidad de abundante agua, como ocurría en San Andrés Calpa.

Finaliza el documento con la suma total de los nopales (nuevos y viejos) cuantificados a lo largo de los márgenes de forma numérica, y textual en el conjunto del documento de la forma siguiente: «Por manera que suman y montan los pies de nopales en las dichas quatro cabeceras: Cholula, Guexosingo, Calpa y San Salvador, setecientos y beynte y un mil y setecientos y sesenta y un pies de nopales viejos, sin más ochocientos y beynte y quatro mil y setecientos y noventa pies que de nuebo sean plantado, que para certificarnos se an hecho tres visitas». La insistencia sobre la revisión de los cálculos de nopales contabilizados, aparece en varias ocasiones a lo largo de la «Relación de lugares...», además de en folio donde se inscribe el cómputo total.

\subsection{El documento de 1600 y la «Relación de Cholula» de 1581}

Puede establecerse una intercambio de información entre «La relación de los lugares y pueblos donde se saca la grana de la ciudad de Cholula» de 1600 y un documento

\footnotetext{
22 Como ejemplo de la naturaleza «catastral» del documento, se informa que los novecientos vecinos de Guexosingo (que en cada casa tienen una nopalera), cultivan una suma que asciende a un total de 33960 pies de nopales viejos y 36720 de nopales nuevos. El documento insiste en la realidad del número de nopales, pues se han hecho hasta tres visitas porque los vecinos de esta ciudad son «araganes y poco aficionados a esta planta», y añade «todos en general son gañanes», es decir, trabajadores de las estancias. Además, se insiste al final de la relación de nopales perteneciente a la ciudad de Guexosingo, que han «andado casa por casa y visitado personalmente y visto la disposición de la tierra y contado los pies de nopales de grana».

23 «Y al sur (Cholula) tiene la Villa de Carrión del Valle de Atlixco, pueblo de españoles labradores, a tres leguas de distancia por camino llano y derecho» (Rojas 1985: 127).

24 San Andrés Calpa es muy probablemente Calpan, que aparece en la Relación de Gabriel de Rojas, al igual que Guexosingo es Huexotzinco, pues se hace referencia a los mismos puntos geográficos, «Tiene esta ciudad (Cholula), cuatro leguas al occidente, la Sierra Nevada, que cae en término de Huexotzinco y Calpan, donde está el volcán que llaman Popocatepetl, que quiere decir «sierra que echa humo» (Rojas 1985: 135).
} 
casi contemporáneo, al que ya se ha hecho referencia, confeccionado por el Corregidor de Cholula, Gabriel de Rojas, en 1581 y conocido como «Relación de Cholula», una descripción de la ciudad que responde a un interrogatorio real para el conocimiento de las Indias, en cuya pregunta veinticinco interroga sobre «si hay seda o grana en la tierra y en qué cantidad» y al que la historiografía ha otorgado credibilidad por el alto conocimiento que de Cholula tenía Gabriel de Rojas (Grunberg 2009). Destaca de esa descripción el número de líneas que dedica a la cochinilla, los nopales y su cultivo, como no podría ser de otra manera dada su importancia en la economía colonial (Sánchez y Suárez 2006: 473-490). Dado que apenas distan dos décadas de la confección de uno y otro documento, resulta interesante reproducir las impresiones y análisis que sobre la grana realizó Gabriel de Rojas.

Tan sólo con prestar atención al gran número de nopales que en los términos catastrados existían, y que conocemos por el documento de 1600, aunque se tome sólo el cultivo de Cholula para su comparación con la obra de Rojas, se puede concluir su importancia dentro de la economía de la ciudad:

«Cógese gran cantidad de grana que llaman cochinillas (...), que, cuando menos se cogen, en sola esta ciudad son dos mil arrobas, poco más o menos, y, cuando más, cuatro mil arrobas, según son los años, fértiles o estériles» (Rojas 1985: 137).

Dedica Gabriel de Rojas una buena parte de su descripción al lugar donde se cría la grana, el nopal, describiendo su morfología y naturaleza. La disposición de los nopales en las tierras parece seguir idéntico modelo a las viñas en España. Esa disposición de los árboles, facilita notablemente su cómputo, objetivo principal del documento «catastral» analizado:

«La cual se cría y coge en un árbol como el de las tunas que se llaman NOPALI, el cual árbol, cuando comienza a nacer, sale una hoja o penca ancha, y de aquéllas salen otras y, de aquéllas, otras, de suerte que ni tiene hojas ni ramas, porque todo él es pencas u hojas más largas que anchas, de grosor de un dedo y dos, y de anchor de una mano y dos. Hácese el árbol, en general, de un estado de alto, cuyo tronco, como va creciendo, se va haciendo rollizo, del tamaño de un muslo de hombre; y siempre este árbol está verde. Están plantados por sus hilos, como las viñas de España» (Rojas 1985: 137).

En el documento objeto de este artículo, se incluye un dibujo reproducido en la Figura $1^{25}$, en el que se pueden apreciar dos «indios» limpiando un nopal. En el suelo aparecen las pencas que han retirado, así como algunos «animales» perjudiciales para la planta. Uno de los indios sigue recortando el nopal y el otro deposita la cochinilla. Ambos aparecen con una indumentaria próxima a la española, si bien el de la izquierda está descalzo. Conocemos por Gabriel de Rojas que acostumbraban a usar «unos pañetes muy estrechos y zapatos a la manera que los usaban los antiguos, como alpargates... y algunos de ellos usan zapatos y, todos, sombreros al uso español» (Rojas 1985: 133).

25 La ilustración aparece descrita de la siguiente forma: «Este nopal está ya i ba podado y limpio de todas las savandijas que la figura de atrás muestra y así se le está hechando la cochinilla para que crie y enjambre y ásele de hechar quando el sol está con más fuerza...». 
Gabriel de Rojas nos describe el modo de cultivar los nopales desde el momento de su plantación, así como los cuidados que requieren. Nos habla también de la poda, de la sujeción del árbol, del aprovechamiento de las pencas que retiran por estar dañadas, así como de algunas otras características del nopal:

«Para plantar un NOPALLI, como quien planta un majuelo, cortan de las pencas de otro y vanlas metiendo solamente un palmo debajo la tierra por su orden, y, como van creciendo, las van apuntalando con unos palos porque, como son tiernas y echan gran cuerpo, se quiebran. Vanlas podando y entresacando algunas pencas tres o cuatro veces en el año, porque, si las dejasen todas, quedaría el NOPALLI muy espeso, de suerte que no le pudiese bañar bien el sol, ni criarse ni cogerse la grana. Críase este árbol para poder dar fruto en un año; son las pencas tan tiernas y aguanosas como un melón. $\mathrm{Y}$ estas pencas que les podan, se las entierran al pie hechas pedazos para que les dé humedad, y, en seis u ocho días, se pudren y se convierten en agua, lo cual no harían si fuesen enteras, porque tornarían a brotar. Es tan fértil y vicioso este árbol, que es menester que las pencas que se han de volver a plantar estén, cortadas del árbol, un mes al sol, porque, si las plantasen luego, no prenderían» (Rojas 1985: 137).

Después de realizar un análisis de la descripción del nopal, y su cultivo, Rojas escribe sobre la grana, pues el nopal al fin y al cabo es un medio para la cría y obtención de la grana cochinilla:

«Tiene este árbol por todo él nacidas muchas espinas, como púas de erizo, y en todas las pencas las hay, así en los llanos como los cantos. Lleva unas tunas pequeñas, coloradas de dentro y fuera cuando están maduras, que son de ningún provecho; que parece que sólo crió Dios este árbol para que en él criase esta grana, a la cual llaman cochinilla por ser casi a modo de las cochinillas. Tiene la propiedad del animalejo que llaman garrapata, de las que crían los perros o bueyes, porque, en naciendo, que es como un arador, se va por la penca del NOPALLI buscando el abrigo. Y, donde se pega, chupa del jugo del nopal, hasta que está crecido del tamaño de una lenteja, y mayor, que tardará en toda su crescencia tres meses. Y, cuando lo quitan o se cae de donde se ha criado, no puede más moverse ni volverse a asir del nopal, aunque le quisiesen volver a asir de él» (Rojas 1985: 137-138).

La reproducción de la cochinilla y los meses para su mejor «cosecha» también se recogen en la «Descripción de Cholula»:

«Dentro de tres meses, o al fin dellos de como nacen, estos animalejos paren gran cantidad de hijuelos, que, al parecer, serán más de doscientos, pequeñitos como aradores, los cuales, de la suerte que la madre, en hallando donde asirse, se quedan hasta que son grandes y paren como está dicho. Y, en pariendo, tienen cuidado los indios de coger las madres, porque, no haciéndolo, se mueren allí. Hay, entre estos hijuelos, algunos dellos con unas alillas a manera de mosquitos, que quiere decir son los machos, los cuales vuelan de un nopal a otro y, al parecer, dentro de un mes se les caen las alillas, y se quedan pegados en el NOPALLI y hechos granos de grana como los demás. La mayor cosecha desta grana es en los meses de más calores, que son mayo, junio, julio y agosto. Para cogerla, tienen los indios cuidado de visitar siempre los nopales y, en viéndola criada, la cogen, teniendo atención a dejar siempre madres para que multipliquen» (Rojas 1985: 138). 
La descripción es bastante elocuente, no sólo en las explicaciones que Gabriel de Rojas da sobre el modo de recolectar la cochinilla, sino también de los utensilios empleados en esa tarea y del procedimiento previo a su comercialización:

«(...) Cogen los indios esta grana, cuando ya está crecida, desta manera: con un hopillo de cola de zorrillo (...) que traen puesto en un palo, limpian la grana, en el nopal donde se ha criado, de una telilla blanca que ella cría sobre sí como telarañas, para ver cuál está crecida, o no; porque, como están muchos granos juntos, con la telilla que crían encima no se dejan ver, y, también, porque les hace provecho la limpieza a los que quedan para criarse. $\mathrm{Y}$, viendo la que está para poder cogerse, con el propio palo en que traen la cola del zorrillo que, por la otra parte, tienen muy adelgazado, la echan abajo grano a grano, y la recogen con una taza hecha de media calabaza (que llaman jícara) que traen en la otra mano. Después de cogida, para matarla, échanla en un lebrillo y refriéganla con la mano, trayéndola alrededor hasta que muere. Algunos, también para matarla, la echan en agua caliente y, después, la ponen a secar al sol (...). Y la compran los españoles por libras y por arrobas, y se navega a España. Van continuamente en las flotas de cuatro mil a doce mil arrobas, como los años acierta, de toda la Nueva España» (Rojas 1985: 139).

La «Relación de Cholula» de Gabriel de Rojas supone un documento prácticamente contemporáneo y complementario de la «Relación de lugares y pueblos de donde se saca la grana de la ciudad de Cholula», pues este último permite cuantificar el número de nopales dando algunas pistas del cultivo, y el primero describe de forma cualitativa la importancia de la grana y todo el proceso de producción. No es posible realizar el estudio de un documento sin hacer referencia al otro, tal y como puede observarse en el análisis documental realizado.

\section{Conclusiones}

Teniendo en cuenta que en un futuro próximo se pretende presentar un estudio pormenorizado del contenido histórico del documento denominado «La relación de los lugares y pueblos donde se saca la grana de la ciudad de Cholula» de 1600, siguiendo las líneas descritas sobre sus posibilidades como fuente histórica en la presente aportación, se pueden adelantar algunas conclusiones sobre su alcance y contenido. El documento es de utilidad para el estudio de los términos que abarca y su entorno en el tránsito del siglo XVI al XVII desde varias perspectivas históricas. Desde el punto de vista toponímico y de organización del territorio la estructuración del documento en estancias permite aproximar la estructura de la propiedad en la época colonial. Desde la perspectiva económica y más concretamente de la economía colonial y del comercio de la grana cochinilla, presenta un acercamiento cuantitativo y, en menor medida, cualitativo al cultivo del nopal y la grana. Desde el aspecto de las relaciones entre indios y españoles muestra la explotación de los primeros, su intervención en la economía colonial y su herencia cultural, además de la presencia y papel de las comunidades religiosas. Desde el ámbito demográfico, se deja constancia del número de vecinos existentes en cada una de las subdivisiones espaciales y en las cuatro áreas geográficas en las que se estructura el documento. Constituye un ejemplo más 
de la importancia de la grana o cochinilla y permite reconstruir su presencia en ese territorio mexicano en torno a 1600 a través del inventario de nopales, dejando constancia de todos y cada uno de los pies de nopales que se cultivaban en Cholula en dicha fecha; se trata, tal como se ha calificado en estas páginas, de un documento «catastral» o de «investigación catastral». La fuente representa un valioso documento para ahondar en el conocimiento demográfico, económico y natural, entre otros, de la América Colonial desde la perspectiva de los archivos españoles y, más concretamente, asturianos, como es el caso del Fondo Documental del Palacio de El Pividal, conservado en el Archivo Histórico de Asturias.

\section{Referencias documentales}

AGI (Archivo General de Indias)

Contratación, 5233, N.42.

AHA (Archivo Histórico de Asturias)

Fondo Pividal, C11248/01 [a]. «Testamento del Licenciado Vasco López de Vivero, Corregidor de la Ciudad de México, otorgado en dicha ciudad, el 12 de abril de 1607. Ante Joan Benito Sánchez». 1607.

Fondo Pividal, C11248/01 [b]. «Memorial de Bienes de la Fundación del Mayorazgo». 1703.

Fondo Pividal, C11248/04. «Testamento otorgado por Dominga de Baldedo, mujer de Vasco López de Vivero, Corregidor que fue de México, otorgado en dicha ciudad, el 28 de agosto de 1597. Ante Juan Benito Camarcho». 1597.

Fondo Pividal, C11248/09. «Información y traslado del testamento otorgado en México, el 16 de octubre de 1597, por Dominga de Veldedo, mujer del Licenciado Vasco López de Vivero Navia y Villaamil, Corregidor de México. Ante Juan Benítez Camacho». 1597.

Fondo Pividal, C11248/21. «Memorial y recibos de lo que se gastó en las exequias y entierro de Dominga de Veldedo, mujer del Licenciado Vasco López de Vivero, en la ciudad de México». 1597-1599.

Fondo Pividal, C11249/01. «Curioso. Relazion de los lugares y pueblos donde se saca la grana de la ciudad de Cholula y sus subxetos echa por Alonso de Nava, Juez de Comisión para el Venefizio della, Por el Ilmo. Señor Conde de Monterrey. Todo lo qual se contiene baxo esta cubierta». 1600.

\section{Referencias bibliográficas}

ANÉs ÁllVAREz de CASTRILlón, Rafael

1987 «Asturias y América: la emigración». Boletín de Letras del Real Instituto de Estudios Asturianos 122: 587-614.

Ansón CaLvo, María del Carmen

1991 «La emigración asturiana en el siglo XVIII. Notas para su estudio», en La emigración española a ultramar, 1492-1914, Antonio Eiras, coord., pp. 77-78. Madrid: Ediciones Tabapress. 
BARreiro Mallón, Baudilio

1991 «Ritmo, causas y consecuencias de la emigración asturiana a América (17001850)», en La emigración española a ultramar, 1492-1914, Antonio Eiras, coord., pp. 41-58. Madrid: Ediciones Tabapress.

Barreiro Mallón, Baudilio y Justo Ureña (eds.)

1992 Avilesinos en América. Avilés: Casa Municipal de Cultura.

Castillo Palma, Norma Angélica

2001 «Cholula en sangre de grana. La destrucción de las nopaleras de cochinilla como resistencia indígena ante el agravio español». Historias 49: 45-66.

CÉspedes Del Castillo, Guillermo

1983 América Hispánica (1492-1898). Barcelona: Editorial Labor.

DAHLGREN, Barbro

1990 La grana cochinilla. México: Instituto de Investigaciones Antropológicas, UNAM.

GARcía Morís, Roberto

2008 «Los Padrones de Moneda Forera como Fuente Histórica para la Edad Moderna Asturiana: El Fondo documental de San Tirso de Abres en el siglo XVII». Boletín de Letras del Real Instituto de Estudios Asturianos 171-172: 245-263.

2012 San Tirso de Abres en el siglo XVII: Población, sociedad y antroponimia. San Tirso: Ayuntamiento de San Tirso de Abres.

Giordano SÁnchez Verín, Carlos Arturo

2010 «Agricultura tradicional en la Nueva España». Revista de Historia Regional 15 (1): 108-130.

GRUNBERG, Bernard

2009 «La «Relación Geográfica de Cholula» o la mirada realista de un investigador sobre el mundo indígena». Estudios de Cultura Náhuatl 40: 281-298.

Martínez Cachero, Luis Alfonso

1976 La emigración asturiana a América. Salinas: Ayalga Ediciones.

Martínez Shaw, Carlos

1994 La emigración española a América (1492-1824). Colombres: Archivo de Indianos.

Pazos Pazos, María Luisa

2003 «Corregidores gallegos en la Nueva España. Apuntes de algunas trayectorias en la administración colonial». Sémata. Ciencias Sociais e Humanidades 15: 445-455.

RoJAs, Gabriel de

1985 «Descripción de Cholula» [1581], en Relaciones Geográficas del siglo XVI. Tlaxcala, Tomo II, René Acuña, ed., pp. 123-145. México: Instituto de Investigaciones Antropológicas, UNAM.

Ruz BArrio, Miguel Ángel

2008 «Cholula durante el siglo XVI: la familia Chimaltecuhtli-Casco». Revista Española de Antropología Americana 38 (1): 7-29.

SÁnchez Silva, Carlos

1998 Indios, comerciantes y burocracia en la Oaxaca poscolonial, 1786-1860. Oaxaca: Instituto Oaxaqueño de las Culturas. 
Sánchez Silva, Carlos y Miguel SuÁrez Bosa

2006 «Evolución de la producción y el comercio mundial de la grana cochinilla, siglos XVI-XIX». Revista de Indias LXVI, 237: 473-490.

SARABIa Viejo, María Justina

1992 «Evolución de los colorantes mesoamericanos en el siglo XVIII», en Europa e Iberoamérica, cinco siglos de intercambio: Actas. IX Congreso Internacional de Historia de América, M Justina Sarabia, coord., Vol. 2, pp. 321-342. Sevilla: Consejería de Cultura, Junta de Andalucía.

1994 La grana y el añil: técnicas tintóreas en México y América Central. Sevilla: Escuela de Estudios Hispano-Americanos.

1998 «La explotación de la grana cochinilla en Nueva España: su organización en el siglo XVI» en VII Congreso Internacional de Historia de América, José Antonio Armillas, coord., Vol. 3, pp. 1829-1834. Zaragoza: Departamento de Educación, Cultura y Deporte, Gobierno de Aragón.

Villaseñor UlloA, Fernando Rafael

2010 «La grana cochinilla y los errores en la interpretación de su historia». Dugesiana 17 (1): 95-100.

Zabalza Seguín, Ana

2015 «Añil, grana y vainillas. Los comerciantes navarros en América Central (siglos XVII-XVIII)» en Identidad y estructura de la emigración vasca y navarra hacia Iberoamérica siglos (XVI-XXI), José Manuel Azcona, ed., pp. 87-110. Pamplona: Thomson Reuters-Aranzadi. 